Manuscript prepared for Atmos. Chem. Phys.

with version 4.2 of the LTEX class copernicus.cls.

Date: 23 February 2013

\title{
Electronic supplement:
}

\section{Aerosol pollution potential from major population centers}

\author{
D. Kunkel $^{1,{ }^{*}}$, H. Tost ${ }^{2}$, and M. G. Lawrence ${ }^{1,{ }^{* *}}$ \\ ${ }^{1}$ Max Planck Institute for Chemistry, PO Box 3020, 55020 Mainz, Germany \\ ${ }^{2}$ Johannes Gutenberg-University, Institute for Atmospheric Physics, 55099 Mainz, Germany \\ * now at: Johannes Gutenberg-University, Institute for Atmospheric Physics, 55099 Mainz, Germany \\ ** now at: Institute for Advanced Sustainability Studies, 14467 Potsdam, Germany
}

\section{Introduction}

This file contains the electronic supplement for: Kunkel et al. (2013): Aerosol pollution potential from major population centers.

The supplement provides additional figures as well as a more comprehensive description of the comparison between the transport of gas-phase transport in EMAC and MATCHMPIC.

\section{Supplement to agricultural and population data}

Figure $\mathrm{S} 1$ shows the fractions of area covered with cropland, pasture, and forest in \% of the data described in Section 2.3. Furthermore the population number is shown in the lower right panel for the year 2005 .

\section{Supplement to model comparison of outflow charac- teristics from major population centers}

We use the same 36 major population centers as in L07 to test the reproducibility of their results. For this we applied EMAC in a setup comparable to the setup of L07 who used the semi-offline, three dimensional, chemical transport model MATCH-MPIC (e.g., Rasch et al., 1997; Lawrence et al., 1999; Kuhlmann et al., 2003). EMAC calculates its own meteorology and is nudged towards meteorological fields from ECMWF in this study whereas MATCH-MPIC relies on a limited set of meteorological input fields, i.e., surface pressure, geopotential, temperature, horizontal winds, surface latent and sensible heat fluxes as well as zonal and meridional wind stresses from NCEP/NCAR reanalysis data (Kalnay et al., 1996) for every six hours. These variables are

Correspondence to: Daniel Kunkel

(dkunkel@uni-mainz.de) interpolated in time to the model time step of 30 minutes, and are used to diagnose online the transport by advection, deep convection, vertical diffusion, and also the hydrological cycle, i.e., water vapor transport, cloud condensate formation, and precipitation. A horizontal resolution of $1.9^{\circ} \times 1.9^{\circ}$ in latitude and longitude, corresponding to T63 with 28 vertical sigma levels was applied from the surface up to $2 \mathrm{hPa}$. To obtain higher accordance in the model setup, EMAC was run in T63 but with 31 hybrid sigma levels in the vertical from the surface up to $10 \mathrm{hPa}$ with a model time step of 15 minutes. Both models rely on different physical parametrizations, e.g., for convection or advection tracer transport algorithms, but on the same convective tracer transport scheme (Lawrence and Rasch, 2005). The main differences between the two models are summarized in Table S1. Furthermore, as 1995 was the year of analysis in L07, we also use the year 1995 for analysis which is "neutral" with regards to ENSO. In both models a passive gas phase tracer was released with a continuous and constant emission rate of $1 \mathrm{kgs}^{-1}$ in each box hosting one of the 36 MPCs.

On the left side in Figure S2 we apply the same color-scale to the EMAC data as L07 did in their Figure 1 (right side of Figure S2). The total column densities look similar in both simulations with only slight differences in the outflow from East Asia over the Pacific Ocean. A large part of the tracer mass in this outflow originates in the Indian subcontinent where convective mass fluxes at $850 \mathrm{hPa}$ and $700 \mathrm{hPa}$ are stronger in EMAC leading to a stronger upward transport of tracer mass. Contrary, the burden in the outflow region from eastern South America over the southern Atlantic Ocean is smaller in the EMAC simulation as convective mass fluxes are higher in the MATCH-MPIC simulation in this region. However, the lifting of tracer mass out of the lowest layers is generally stronger in EMAC and consequently the surface densities in MATCH-MPIC simulations are higher, although the surface layer is slightly deeper for MATCH-MPIC with about $80 \mathrm{~m}$ in contrast to about $60 \mathrm{~m}$ in case of EMAC. 

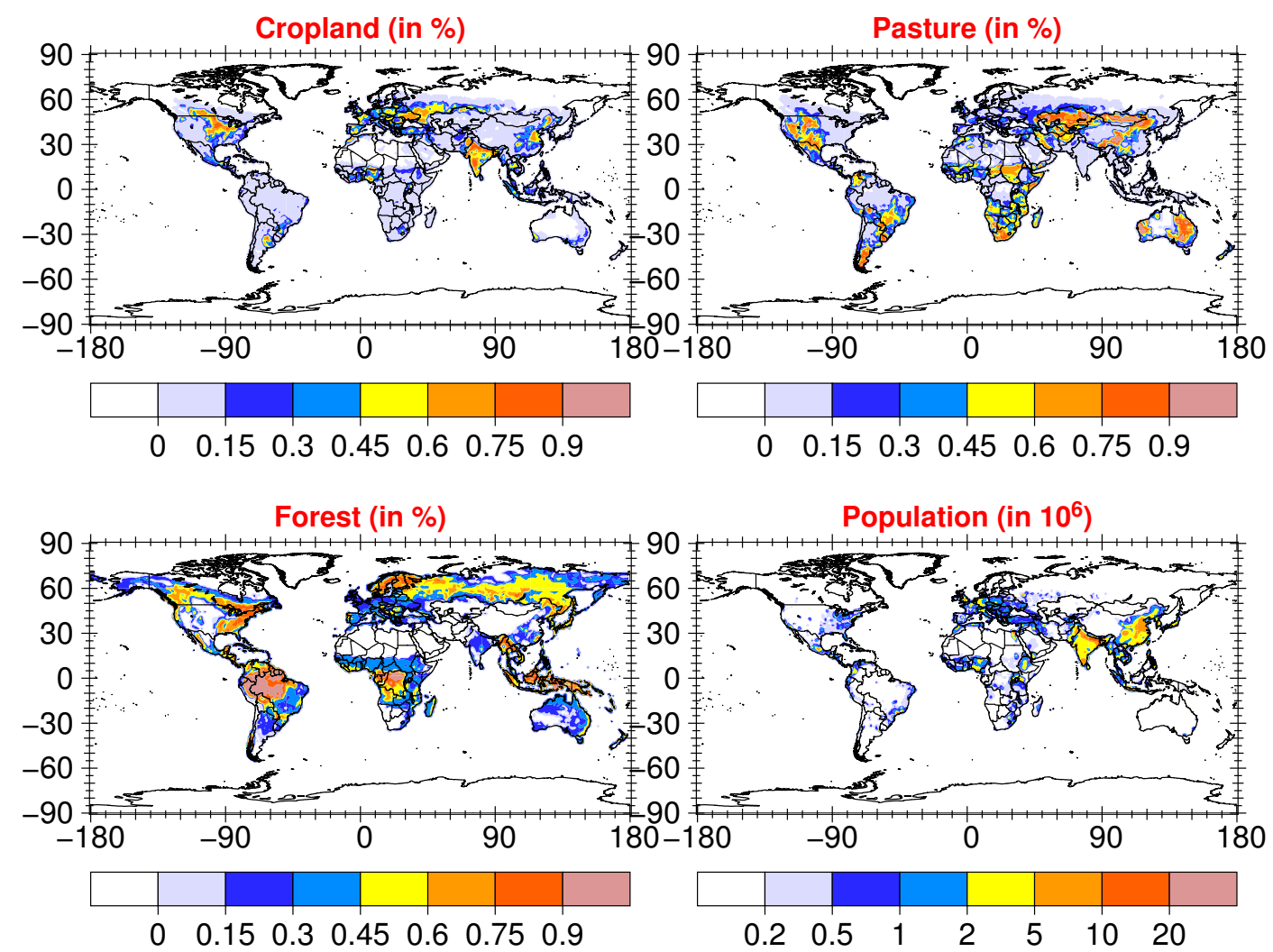

Fig. S 1. Fraction of the area covered with cropland (upper left), pasture (upper right), and forest (lower left) in \%. Population number for the year 2005 in $10^{6}$ person/box (lower right).

We further apply the metrics $E L R_{1 \mathrm{~km}}, E_{\mathrm{UT}}$ and $A_{10}$ to our model data and compare it to the results reported in L07. Figure $\mathrm{S} 3$ shows the corresponding scatter plot of the three metrics for each major population center. A fairly good agreement is achieved for all three metrics which is supported by high coefficients of determination $\left(R^{2}\right.$, based on the Pearson correlation coefficient) of $0.78\left(E L R_{1 \mathrm{~km}}\right), 0.72\left(E_{\mathrm{UT}}\right)$ and $0.75\left(A_{10}\right)$. The explanation of missing variance (about one quarter) is attributable to uncertainties in the underlying meteorological fields as well as model uncertainties, e.g., parametrizations for sub-grid scale processes or errors introduced by the numerical representation of physical equations.

Moreover, Table $\mathrm{S} 2$ provides a city by city listing of differences in the annual mean of the metrics, $E L R_{1 \mathrm{~km}}, E_{\mathrm{UT}}$ and $A_{10}$, and in the calculated ranks of each MPC. On average metrics calculated from MATCH-MPIC simulations show larger low-level outflow (negative mean in $E L R_{1 \mathrm{~km}}$ ) and a larger area with a mass threshold exceedance of $10 \mathrm{ngm}^{-3}$ (negative mean in $A_{10}$ ) while the upper tropospheric pollution $E_{\mathrm{UT}}$ is larger in EMAC. Often a change for an MPC in low-level pollution is accompanied by a change in upper level pollution of opposite sign. In addition, these results are consistent with findings in Figure S2 that in the case for
EMAC simulations the ventilation of the boundary layer is stronger than for MATCH-MPIC due to generally more vertical transport. Maximum changes for $E L R_{1 \mathrm{~km}}$ are found for Moscow with $-11 \%$ and $+3.1 \%$ for Rio de Janeiro while most MPCs range between $-1.0 \%$ and $-6.0 \%$. Changes in $E_{\text {UT }}$ cover a broad range with $16 \%$ more mass above $5 \mathrm{~km}$ in MATCH-MPIC results for Rio de Janeiro while Mumbai has about $14 \%$ more mass in the upper troposphere in the EMAC results. For $A_{10}$ there is one outlier, Moscow, which shows a larger difference of $5.9 \times 10^{6} \mathrm{~km}^{2}$ while most other cities do not differ more than $2.7 \times 10^{6} \mathrm{~km}^{2}$.

In general, the main results from L07 are well reproduced when using EMAC which underlines the robustness of the results. The metrics mainly depend on the underlying meteorological fields and advective and convective transport schemes, which introduce the largest uncertainties in such calculations.

\section{Seasonal metrics for the aerosol outflow}

In this section the seasonal means of $R C L_{0.5 \mathrm{~km}}, E_{\mathrm{UT}}$, and $E L R_{1 \mathrm{~km}}$ are provided for winter (DJF), spring (MAM), summer (JJA), and autumn (SON) from top to bottom in Fig- 

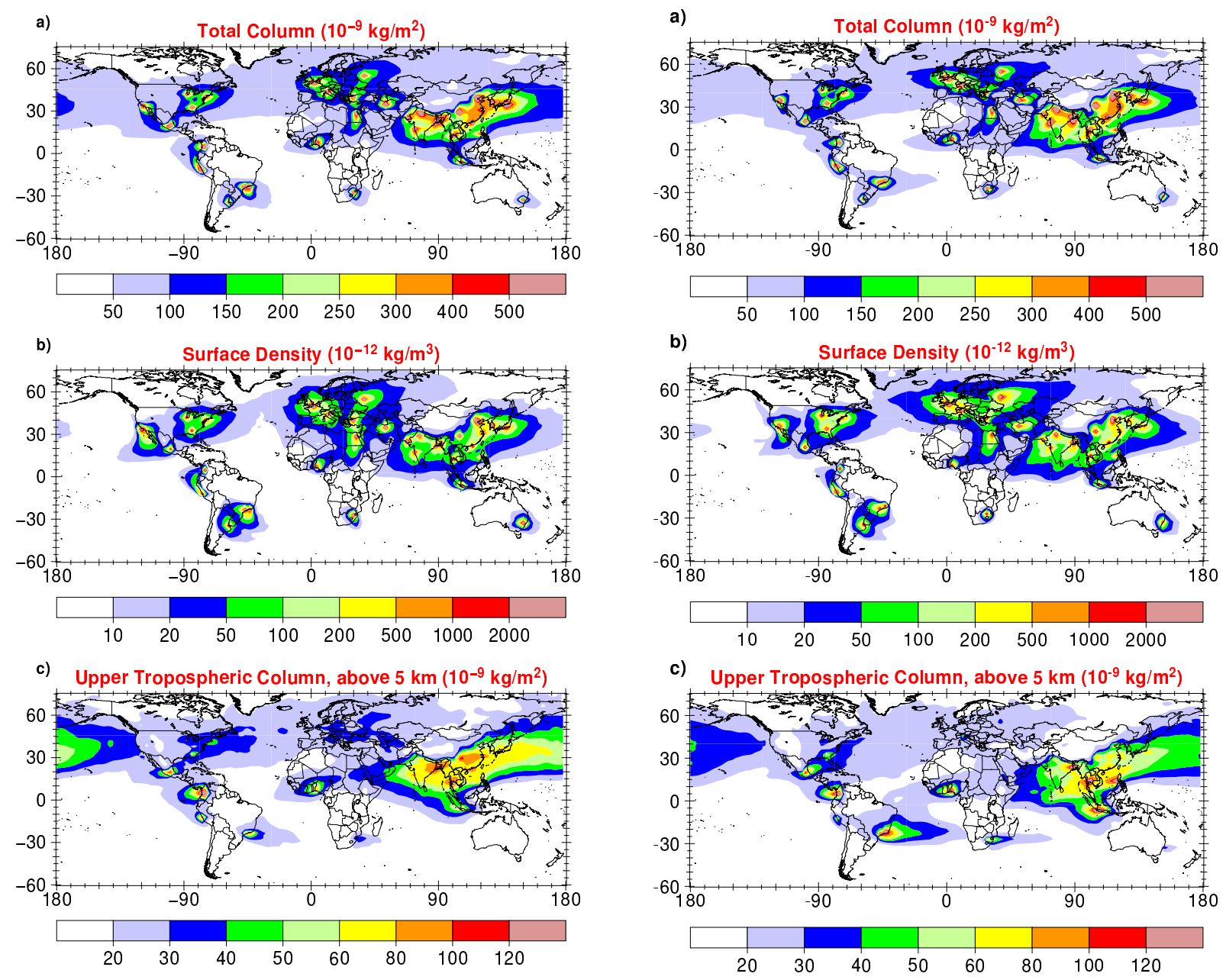

Fig. S 2. Annual mean sum for a) the total column density in $10^{-9} \mathrm{~kg} \mathrm{~m}^{-2}$, b) the surface density in $10^{-12} \mathrm{~kg} \mathrm{~m}^{-2}$, and c) upper tropospheric column above $5 \mathrm{~km}$ in $10^{-9} \mathrm{kgm}^{-2}$. On the left for EMAC simulations, on the right adopted from Lawrence et al. (2007), copyright 2007 by the European Geophysical Union.

Table S 1. Differences in model setup between EMAC and MATCH-MPIC.

\begin{tabular}{lll}
\hline & EMAC & MATCH-MPIC \\
\hline Vertical levels & 31 & 28 \\
Uppermost level ends at & $10 \mathrm{hPa}$ & $2 \mathrm{hPa}$ \\
Meteorological data & ECMWF & NCEP/NCAR reanalysis data \\
Coupling & online & semi-offline \\
Time step & 15 min & 30 min \\
Advection & Lin and Rood (1996) & Rasch and Lawrence (1998) \\
Convection & Tiedtke (1989) & Zhang and McFarlane (1995) \\
& Nordeng (1994) & Hack (1994) \\
\hline
\end{tabular}

ure S4. Results from MPCs from the Southern Hemisphere have been shifted by six months to be in accordance with the Northern Hemispheric seasonal cycle. Colors indicate the region of the averaging: all MPCs (black), tropical (red), arid (brown), temperate no dry (light green), temperate summer dry (dark green), temperate winter dry (light blue), and cold (blue). This figure is discussed in Section 4 of the publication. 
Table S 2. Differences between EMAC and MATCH-MPIC annual values and corresponding ranks for $E L R_{1 \mathrm{~km}}, E_{\mathrm{UT}}$, and $A_{10}$ for the 36 MPCs: $\bar{x}$, mean differences; $x_{d}$, corresponding mean absolute deviations, with $\bar{x}=\Sigma_{i=1}^{N} x_{i} / N, x_{d}=\Sigma_{i=1}^{N}\left|x_{i}^{\prime}\right| / N, x_{i}^{\prime}=x_{i}-\bar{x}, x_{i}$ metric value of an MPC, and $N$ total number of MPCs.

\begin{tabular}{|c|c|c|c|c|c|c|}
\hline & $\begin{array}{c}E L R_{1 \mathrm{~km}} \\
\%\end{array}$ & Rank & $\begin{array}{c}E_{\mathrm{UT}} \\
\%\end{array}$ & Rank & $\begin{array}{c}A_{10} \\
\times 10^{6} \mathrm{~km}^{2}\end{array}$ & Rank \\
\hline \multicolumn{7}{|l|}{ Europe } \\
\hline London & -4.14 & 0 & 5.08 & 0 & -2.07 & 4 \\
\hline Paris & -3.9 & 0 & 5.22 & 0 & -1.96 & 1 \\
\hline Moscow & -11.03 & 0 & 6.32 & 0 & -5.92 & 1 \\
\hline Po Valley & -2.11 & -4 & 5.43 & 2 & -0.8 & -4 \\
\hline \multicolumn{7}{|l|}{ West Asia } \\
\hline $\begin{array}{l}\text { Teheran } \\
\text { Africa }\end{array}$ & -7.37 & 11 & 8.08 & -1 & -1.64 & 7 \\
\hline Cairo & -5.47 & 2 & 9.72 & -5 & -0.95 & -2 \\
\hline Lagos & -1.25 & 5 & -2.38 & 0 & 1.1 & -4 \\
\hline \multicolumn{7}{|l|}{ Southern Asia } \\
\hline Karachi & -5.12 & 6 & 8.27 & -9 & -1.19 & -3 \\
\hline Mumbai & -4.72 & 5 & 13.84 & -9 & -1.68 & 3 \\
\hline Delhi & -8.28 & 12 & 10.62 & -9 & -2.66 & 7 \\
\hline Kolkata & -5.75 & 9 & 10.44 & -6 & -1.26 & 2 \\
\hline Dhaka & -6.93 & 10 & 8.91 & -8 & -1.69 & 6 \\
\hline \multicolumn{7}{|l|}{ Eastern Asia } \\
\hline Szechuan Basin & -1.09 & 4 & 8.28 & -5 & -0.55 & 4 \\
\hline Beijing & -5.67 & 6 & 4.45 & -3 & -2.34 & 7 \\
\hline Tianjin & -4.53 & 4 & 3.31 & -2 & -2.24 & 7 \\
\hline Shanghai & -4.31 & 4 & 0.45 & -1 & -1.49 & 1 \\
\hline Seoul & -1.52 & -6 & 0.57 & 3 & -0.21 & -10 \\
\hline Tokyo & 1.97 & -9 & -7.04 & 7 & 0.39 & 0 \\
\hline Osaka & 0.32 & -7 & -4.14 & 3 & -0.28 & -4 \\
\hline \multicolumn{7}{|l|}{ Southeast Asia } \\
\hline Manila & 2.86 & -6 & -14.81 & 4 & 0.83 & -5 \\
\hline Bangkok & -0.93 & 4 & -4.02 & -1 & -0.45 & 5 \\
\hline $\begin{array}{l}\text { Jakarta } \\
\text { Australia }\end{array}$ & \multicolumn{5}{|c|}{ Australia } & -3 \\
\hline $\begin{array}{l}\text { Sydney } \\
\text { North America }\end{array}$ & 1.95 & -9 & -7.53 & 9 & -0.01 & 2 \\
\hline Chicago & -3.7 & 1 & 1.92 & 0 & -2.05 & 5 \\
\hline New York & -1.06 & -6 & -0.55 & 3 & -0.9 & -4 \\
\hline Los Angeles & 0.84 & -10 & 1.66 & 2 & -0.08 & -11 \\
\hline Atlanta & -1.08 & -4 & -2.97 & 3 & -1.4 & 4 \\
\hline Mexico City & -0.72 & 0 & -3.81 & 2 & -0.18 & 1 \\
\hline \multicolumn{7}{|l|}{ South America } \\
\hline Bogotá & -2.1 & 1 & 9.61 & -5 & -0.01 & 0 \\
\hline Lima & -0.82 & -5 & 7.17 & -6 & -0.16 & -3 \\
\hline Rio de Janeiro & 3.1 & -6 & -16.26 & 9 & 0.55 & -2 \\
\hline São Paulo & 2.18 & -5 & -14.1 & 9 & 0.22 & 3 \\
\hline Buenos Aires & 0.22 & -6 & -2.66 & 7 & -0.24 & -10 \\
\hline $\bar{x}$ & -2.32 & 0 & 1.05 & 0 & -0.91 & 0 \\
\hline$x_{d}$ & 2.88 & 4.89 & 6.41 & 3.94 & 0.99 & 4.06 \\
\hline
\end{tabular}




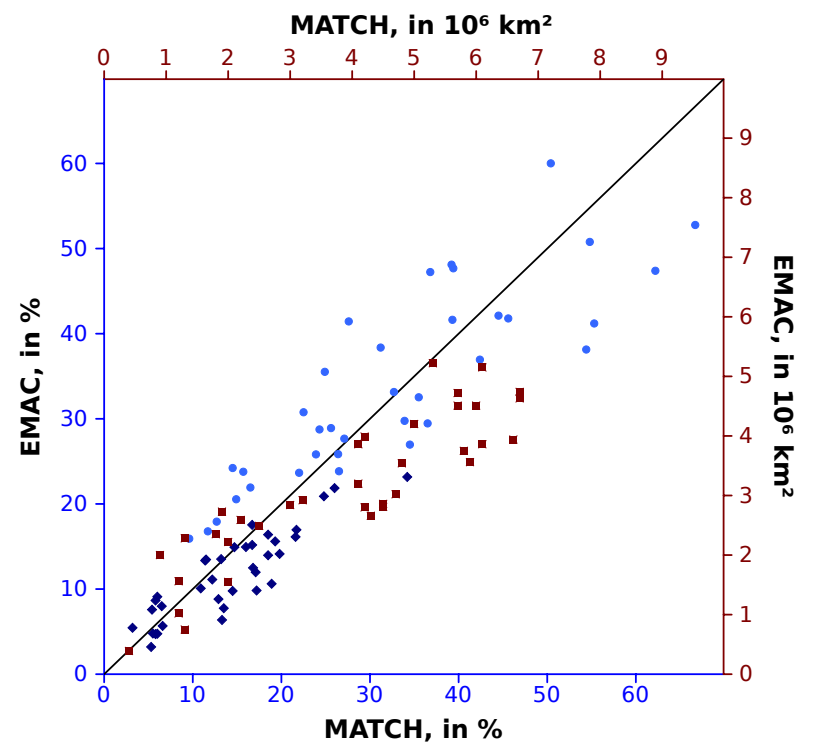

Fig. S 3. Scatter plot of $E L R_{1 \mathrm{~km}}$ (dark blue diamonds), $E_{\mathrm{UT}}$ (light blue dots), and $A_{10}$ (red squares) obtained from EMAC (ordinate) and MATCH-MPIC (abscissa) data.

\section{Supplement to: Impact of high concentrated deposi- tion on ecosystem}

Figure S5 shows the individual areas of cropland, pasture, and forest which are covered with at least $1 \%$ of the emission of an MPC $\left(D_{1}\right)$ for $1.0 \mu \mathrm{m}$ (left) and $10.0 \mu \mathrm{m}$ (right) aerosol tracers. This figure is discussed in Section 6.1.2 in the manuscript.

\section{References}

Hack, J. J.: Parameterization of moist convection in the National Center for Atmospheric Research community climate model (CCM2), Journal of Geophysical Research, 99, PP. 5551-5568, doi:199410.1029/93JD03478, 1994.

Kalnay, E., Kanamitsu, M., Kistler, R., Collins, W., Deaven, D., Gandin, L., Iredell, M., Saha, S., White, G., Woollen, J., Zhu, Y., Leetmaa, A., Reynolds, R., Chelliah, M., Ebisuzaki, W., Higgins, W., Janowiak, J., Mo, K. C., Ropelewski, C., Wang, J., Jenne, R., and Joseph, D.: The NCEP/NCAR 40-Year Reanalysis Project, Bulletin of the American Meteorological Society, 77, 437-471, doi:10.1175/1520-0477(1996)077〈0437:TNYRP $\rangle$ 2.0.CO;2, 1996.

Kuhlmann, R. v., Lawrence, M. G., Crutzen, P. J., and Rasch, P. J.: A model for studies of tropospheric ozone and nonmethane hydrocarbons: Model description and ozone results, Journal of Geophysical Research, 108, 22 PP, 2003.
Lawrence, M. G. and Rasch, P. J.: Tracer Transport in Deep Convective Updrafts: Plume Ensemble versus Bulk Formulations, J. Atmos. Sci., 62, 2880-2894, doi:10.1175/JAS3505.1, 2005.

Lawrence, M. G., Crutzen, P. J., Rasch, P. J., Eaton, B. E., and Mahowald, N. M.: A model for studies of tropospheric photochemistry: Description, global distributions, and evaluation, Journal of Geophysical Research, 104, 26,245-26,277, 1999.

Lin, S. and Rood, R. B.: Multidimensional Flux-Form SemiLagrangian Transport Schemes, Monthly Weather Review, 124, 2046-2070, doi:10.1175/1520-0493(1996)124〈2046:MFFSLT〉 2.0.CO;2, 1996.

Nordeng, T.: Extended versions of the convective parametrization scheme at ECMWF and their impact on the mean and transient activity of the model in the tropics, Technical memorandum, ECMWF, Reading, UK, 1994.

Rasch, P. J. and Lawrence, M.: Recent developments in transport methods at NCAR, Tech. Rep. 265, Hamburg, Germany, edited by B. Machenhauer, 1998.

Rasch, P. J., Mahowald, N. M., and Eaton, B. E.: Representations of transport, convection, and the hydrologic cycle in chemical transport models: Implications for the modeling of short-lived and soluble species, Journal of Geophysical Research, 102, PP. 28,127-28,138, doi:199710.1029/97JD02087, 1997.

Tiedtke, M.: A Comprehensive Mass Flux Scheme for Cumulus Parameterization in Large-Scale Models, Monthly Weather Review, 117, 1779-1800, 1989.

Zhang, G. and McFarlane, N. A.: Sensitivity of climate simulations to the parameterization of cumulus convection in the Canadian climate centre general circulation model, Atmosphere-Ocean, 33, 407-446, doi:10.1080/07055900.1995.9649539, 1995. 


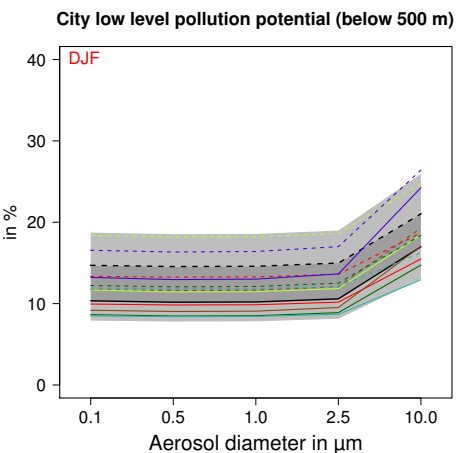

City low level pollution potential (below $500 \mathrm{~m}$ )

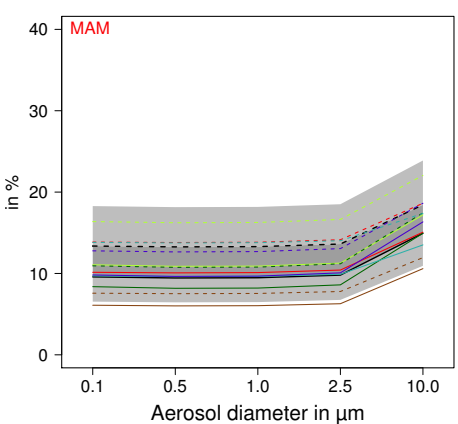

City low level pollution potential (below $500 \mathrm{~m}$ )

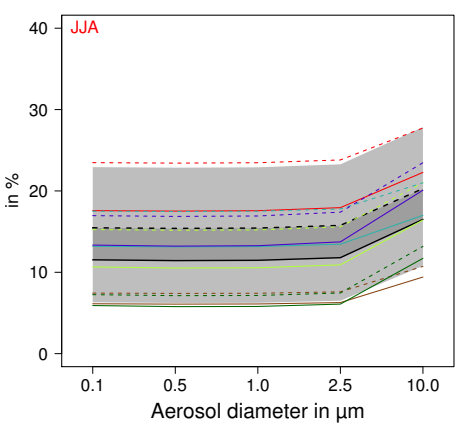

City low level pollution potential (below $500 \mathrm{~m}$ )

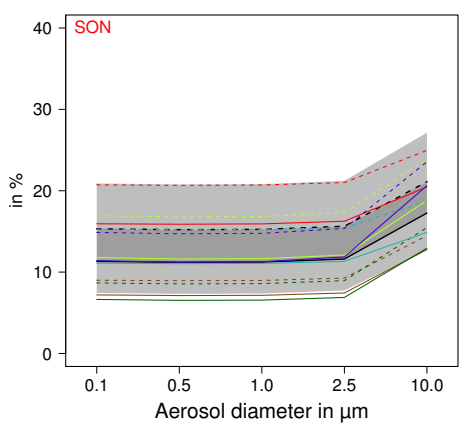

Remote low level pollution potential (below $1000 \mathrm{~m}$ )

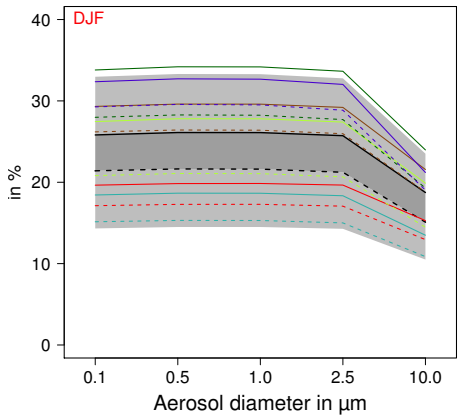

Remote low level pollution potential (below $1000 \mathrm{~m}$ )

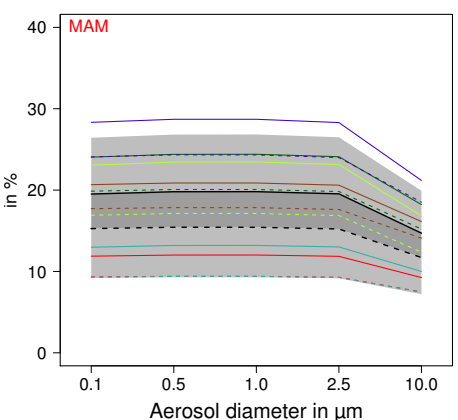

Remote low level pollution potential (below $1000 \mathrm{~m}$ )

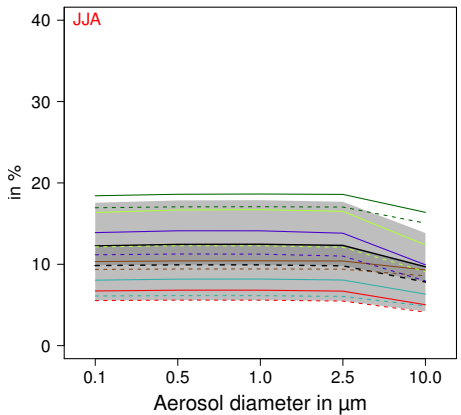

Remote low level pollution potential (below $1000 \mathrm{~m}$ )

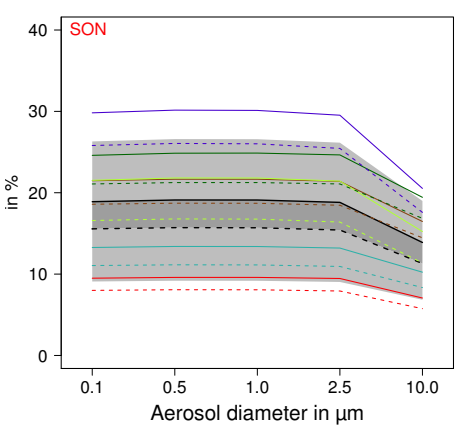

Upper tropospheric pollution potential

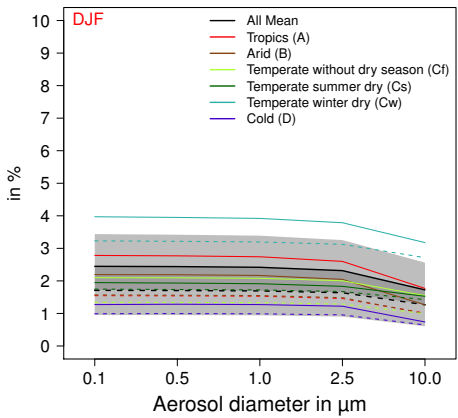

Upper tropospheric pollution potential

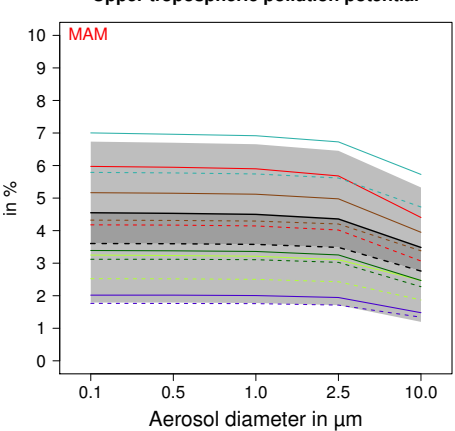

Upper tropospheric pollution potential

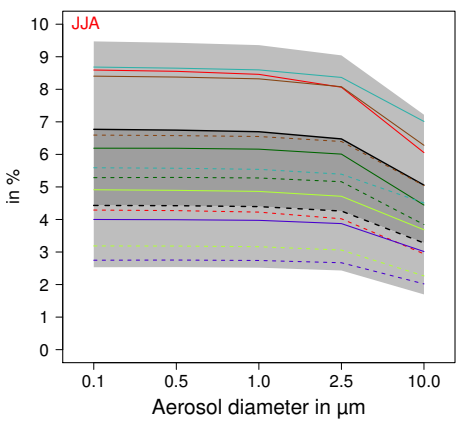

Upper tropospheric pollution potential

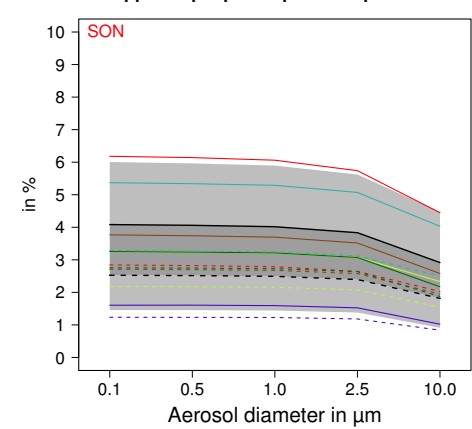

Fig. S 4. Seasonal means of $R C L_{0.5 \mathrm{~km}}$ (left panels), $E L R_{0.5 \mathrm{~km}}$ (middle panels), and $E_{\mathrm{UT}}$ (middle panels) for winter (DJF), spring (MAM), summer (JJA) and autumn (SON) from top to bottom. Results from the Southern Hemisphere have been shifted by six months to be in accordance with the Northern Hemispheric seasonal cycle. Colors indicate the region of the averaging: all MPCs (black), tropical (red), arid (brown), temperate no dry (light green), temperate summer dry (dark green), temperate winter dry (light blue), and cold (blue). Dashed lines represent $\mathrm{NS}_{\mathrm{act}}$, solid lines $\mathrm{NS}_{\text {inact }}$ averages. 

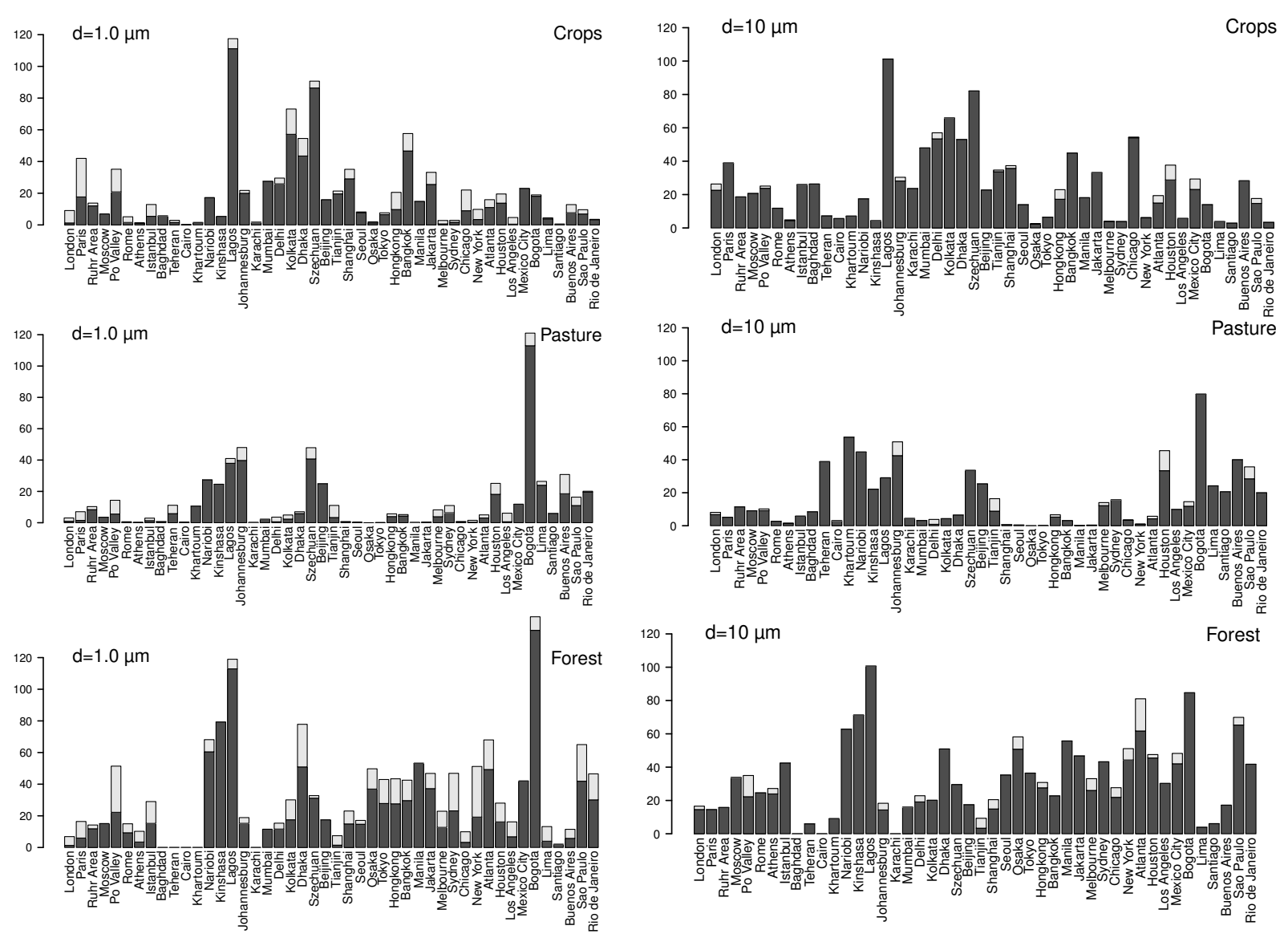

Fig. S 5. Cropland, pasture, and forest areas covered with at least $1 \%$ of the emission of an MPC $\left(D_{1}\right)$ for $1.0 \mu \mathrm{m}$ (left) and $10.0 \mu \mathrm{m}$ (right) aerosol tracers. Dark gray bars show the minimum area covered by either the $\mathrm{NS}_{\text {act }}$ or $\mathrm{NS}_{\text {inact }}$ tracers, light gray bars show the additional area by the tracer with the other NS state. 